\title{
Erken çocukluk döneminde bebeklik/çocukluk amnezisi ve otobiyografik bellek gelişimi
}

\author{
Infancy/childhood amnesia in early childhood and development of \\ autobiographical memory
}

Kızbes Meral Kılıç ${ }^{1}$

\begin{abstract}
Makale Geçmişi
Geliş : :03 Mayıs 2019

Düzeltme : 17 Haziran 2019

Kabul : 20 Haziran 2019

Çevrimiçi : 04 Ekim 2019
\end{abstract}

\section{Makale Türü}

Derleme Makale

\section{Article History}

Received : 03 May 2019

Revised : 17 June 2019

Accepted : 20 June 2019

Online : 04 October 2019

\section{Article Type}

Revien Article

\begin{abstract}
Öz: Kişinin kendi geçmişindeki düşünceleri, duyguları ve davranışları hakkındaki anılarından oluşan otobiyografik bellek, çeşitli işlevleri bakımından çocuğun gelişiminde önemli bir kavramdır. Otobiyografik belleğin benlik gelişimine etkisi büyüktür. Kişilerin benlik devamlılığını, öz-düzenleme ihtiyaçlarını karşılayabilmelerini ve geçmiş yaşantı ve deneyimlerinden edinilen dersler sayesinde şimdi ve gelecekteki davranışlar hakkında çıkarsamalarda bulunup planlama yapabilmeyi sağlayan otobiyografik bellek, sosyal ilişkiler için de temel öneme sahiptir. Kişisel geçmişimizde sürekliliği sağlayan otobiyografik bellek gelişimi çoğu yetişkin yaşamının ilk üç-dört yılını hatırlayamadığı bebeklik/çocukluk amnezisinin bitiminde başlamaktadır. Erken dönem deneyimleri ilerleyen yaşlarda kritik öneme sahiptir. Hatırlanamadığı halde yetişkin yaşamını önemli derecede etkileyen bebeklik/çocukluk amnezisi, üzerinde uzunca süredir çalışılmış bir konudur. Bu çalışmada, otobiyografik bellek, otobiyografik belleğin gelişimi ve bebeklik/çocukluk amnezisi incelenmiş ve çocuk gelişimi bağlamında bazı önerilerde bulunulmuştur.
\end{abstract}

Anahtar Kelimeler: Otobiyografik Bellek; Otobiyografik Bellek Gelişimi; Bebeklik/Çocukluk Amnezisi

Abstract: Autobiographical memory consists of memories of one's own thoughts, feelings and behaviors in his/her own history. Autobiographical memory is an important concept in the development of the child in terms of various functions. The effect of autobiographical memory on self development is great. Autobiographical memory ensures the self-continuity of individuals, meets the needs of selfregulation. Autobiographical memory, through lessons learned from past experiences and experiences, makes inferences and planning about the behaviors of the present and the future. Autobiographical memory is also essential for social relations. The development of autobiographical memory, which provides continuity in our personal history, begins at the end of infancy/childhood amnesia where most adults cannot remember the first three-four years of life. Early experiences are critical in advancing age. Infant/childhood amnesia, which has a significant effect on adult life although it cannot be remembered, has been studied for a long time. In this study, autobiographical memory, development of autobiographical memory, and infancy/childhood amnesia were examined and some suggestions were made in the context of child development.

Keywords: Autobiographical Memory; Development of Autobiographical Memory; Infancy / Childhood Amnesia 


\section{SUMMARY}

\section{Introduction}

We all have a self that is formed as a result of our personal experiences, and memories that enable us to remember that self (Bauer, 2015: 204). Throughout our lives, we use our memory processes efficiently in all the cognitive processes that we have learned before and will learn hereafter. Thanks to our memories of the past, we believe that we were the same person yesterday and are today (Bauer, 2015: 204). The experiences such as our siblings' birth, if we have any, our first teacher, our childhood friends, the games we played as a child, the things we experienced and enjoyed for the first time, the story of moving, the loss of a relative, and the experiences we had with our family members etc. are unique, just like our fingerprints; and they are memories that only belong to us. There is a discontinuity in our autobiographical memory, which allows us to remember the life events and all of our special experiences that are important in our lives. Most adult individuals cannot remember the first three to four years of their lives. It is observed that there are increasing number of memories between the ages of three and seven. In later stages, it is assumed that the distribution of the personal memories has a similar pattern to that of the adults (Bauer, 2015: 204). This period, which cannot be remembered consciously, is named as "Infantile/Childhood Amnesia" in the related literature.

In this study, autobiographical memory, in which people use their own experiences to solve the problems encountered in daily life, and infantile/childhood amnesia that is closely related to autobiographical memory will be discussed and examined in the context of various variables; and suggestions will be made in the field of child development.

\section{Autobiographical Memory}

The memories in the autobiographical memory are memories of one's own thoughts, feelings and behaviors in his/her own past (Budak, 2003: 554). Autobiographical memory means one's recalling of important events and experiences of their own lives; and it helps them build personal life histories and ensures that they associate their experiences with others' and create socially shared memories (Kail, 2012:216). It is thought that autobiographical memory encompasses the information that comes from both episodic and semantic memory. Autobiographical memory is the information of self-knowledge and the memories surrounding this personal knowledge. The memories in autobiographical memory can also represent other knowledge types such as procedural learning (driving a car, playing tennis) (Roediger and Marsh, 2003: 476).

\section{Infantile/Childhood Amnesia}

Although the neural "equipment" that is needed to encode, store and retrieve the information (the things that are seen, heard, thought, felt etc.) is present at birth (and before), the memories of very young children are quite vulnerable. Many studies have been done in the literature for this phenomenon and there is an agreement on that this early-life memory paucity leads to "infantile/childhood amnesia"; and that adults cannot remember the events that happened during infancy and toddler years. (Schneider, 2015: 102)

Freud developed the "Infantile Amnesia Theory" on the basis of his observations on his adult patients who rarely remembered the memories of their early years (Josselyn and Frankland, 2012: 423). Even though the explanations of Freud on the issue that adults cannot remember their early-life memories are not widely accepted anymore; the term "Infantile/Childhood Amnesia" he used to define the phenomenon is a part of his lasting legacy (Jack and Hayne, 2010:831). In the studies conducted in the field of "infantile/childhood amnesia", it is stated that the infancy/childhood experiences are crucially important for brain functions for the entire life (Alberini and Travaglia, 2017: 5783). It is evidenced that early-life experiences have profound effects on the brain functions and brain physiology in later stages. For example, as time passes, the 
threatening experiences that occur in the early stages of life may lead to psychopathologies such as posttraumatic stress disorder and anxiety disorders. This paradox raises the question of how early-life memories can affect adult life even though they cannot be remembered.

Several hypotheses have been proposed to explain this paradox. One suggests that infantile/childhood amnesia results from the immaturity of the infants' brains (Travaglia, Bisaz, Sweet, Blitzer and Alberini, 2016: 1225-1226). In recent studies, it is indicated that rapid forgetting, which is one of the immature functions of infant brain, prevents memory consolidation (the process by which information is placed in the memory and become stable) that serves to store the memories which belong to the long-term memory and to make them permanent in long-term memory. On the other hand, some researchers have suggested that latent, not expressed memory traces of infantile/childhood amnesia impact behaviors later in life because information cannot be reinstated from long-term memory (Travaglia et al., 2016: 1226). When the related literature is reviewed, it is seen that autobiographical memory performances of people with autism are lower than those of without autism (Crane and Goddard, 2008; Goddard, Howlin, Dritschel and Patel, 2000; Millward, Powell, Messer and Jordan, 2000). Autobiographical memory difficulties observed in the individuals with autism which is a neurodevelopmental disorder with social interactions and communication problems is important in terms of revealing the relationship between autobiographical memory performance and language and brain development.

\section{Development of Autobiographical Memory}

The period between 18 and 24 months, in which infants start to recognize themselves in the mirror, is significant for autobiographical memory development. Unlike mothers who adopt a "low elaborative" conversational style with their children; mothers who adopt a "high elaborative" conversational style generally ask more questions to their children and link the experience at issue to other experiences (Langley, Coffman and Ornstein, 2017). Autobiographical memory, which is the result of the communication and interaction of a child with others, his/her language development and the development of his/her memory structures and processes, continues to develop for the first 5 years of age (Nelson and Fivush, 2004).

In studies involving participants raised in different cultures, it is observed that individuals raised in Eastern cultures recall events that occurred after 3.5 years of age; about 6 months later than individuals in Western cultures (Wang, Conway and Hou, 2004: 123). It is stated that the individuals raised in Western cultures share elaborative memories from specific autobiographical memory focusing on their own actions, thoughts and feelings; while the individuals from Eastern cultures, taking into account their own actions, share their memories from autobiographical memory which are more general, less detailed and placed in a more common framework regarding group's norms and needs (Wang and Ross 2007). Some researchers say that women can remember their memories from infancy more than men; and some researchers say that there is no difference between men and women in this regard. (Peterson, Grant and Boland, 2005:624).

\section{Conclusion and Discussion}

For the development of autobiographical memory which is significant for social relationships, parents can reminisce with children about the past beginning from early periods. While talking about the past with children, it is important to engage in high-elaborative reminiscing instead of low-elaborative reminiscing. In a conversation with a child, it is essential to ask more open-ended questions about the experiences s/he had, to ensure that $\mathrm{s} /$ he can link the current experiences to previous experiences and to the possible events in the future. To improve autobiographical memory, it is also important that the parent or the adult communicating with the child give examples of his/her autobiographical memory processes. Looking through the old photos and videos together with children and discussing them may strengthen autobiographical memory, as well. Beginning from the early stages, children can evaluate their past well, learn from their correct and incorrect behaviors, thereby make proper decisions and follow them. 
The early childhood period coincides with the end of infancy/childhood amnesia and the beginning of autobiographical memory. In this period, the relationships between the children's cognitive, emotional, social and language development and their autobiographical memory performance; and the different variables that may affect children's lives deeply such as neglect, abuse, migration, exposure to traumatic experiences, adoption, being separated from parents for various reasons, death of the parents, and autobiographical memory relationships have been researched on. The conducting of these researches is thought to contribute especially to the national literature. 


\section{GİRIŞ}

Hepimizin kişisel yaşantıları sonucu oluşmuş bir benliği ve bunu hatırlayabilmemizi sağlayan bellekleri bulunmaktadır (Bauer, 2015: 204). Tüm yaşamımız boyunca eski öğrendiklerimiz ve yeni öğreneceğimiz tüm bilişsel süreçlerde bellek süreçlerimizi etkin biçimde kullanırız. Bellek süreçleri içinde yabancı dil ve bir müzik enstrümanı kullanmayı öğrenme gibi daha önceden bilmediğimiz eylemler yer alabildiği gibi, daha önce tanıştı̆̆ımız bir kişinin adını hatırlama, okuma, yazı yazma gibi daha önceden öğrenmiş olduğumuz eylemler ve bizim için çok önemli olan yaşantılarımız da yer alabilir Bellek süreçlerinin katkısıyla oluşan deneyimlerimiz, benliğimizin gelişimi için de kritik öneme sahiptir. Zaman içinde süreklilik ve tutarlılık duygumuz, geçmişte meydana gelen olayların ve deneyimlerin anılarına dayanır (Bauer, 2015: 204). Böylece, daha önceden öğrendiklerimizi her gün yeniden öğrenmemize gerek kalmaz.

Geçmişe ait anılarımız sayesinde, dün ve bugün aynı kişi olduğumuza inanırız (Bauer, 2015: 204). Varsa, kardeşimizin doğumu, ilk öğretmenimiz, çocukluk arkadaşlarımız, çocukken oynadığımız oyunlar, ilk kez deneyimlediğimiz ve yapmaktan hoşlandığımız şeyler, aile üyelerimizle yaşadıklarımız, taşınma öykümüz, bir yakınımızın kaybı vb. deneyimler tıpkı parmak izimiz gibi biriciktir ve sadece bize ait olan anılardır.

Otobiyografik belleğe ait anıları ne zamandan itibaren hatırlayabilmekteyiz? Yaşamımızda önemli olan yaşam olaylarını ve bize özel deneyimlerin hepsini hatırlamamızı sağlayan otobiyografik belleğimizde bir süreksizlik bulunmaktadır. Çoğu yetişkin birey, yaşamının ilk üç-dört yılını hatırlayamamaktadır. Üç ile yedi yaşları arasında giderek artan sayıda anıların olduğu görülmektedir. Daha sonraki dönemlerde kişisel anıların yetişkinlere benzer bir dağılımı olduğu varsayılmaktadır (Bauer, 2015: 204). Bilinçli olarak hatırlanamayan bu süre, ilgili alan yazında "Bebeklik/Çocukluk Amnezisi” olarak adlandırılmaktadır.

$\mathrm{Bu}$ çalışmada, kişinin günlük yaşamda karşılaştığı sorunları çözebilmede kendi yaşantı ve deneyimlerini esas aldığı otobiyografik bellek ve otobiyografik bellek ile yakından ilişkili olan bebeklik/çocukluk amnezisi çeşitli değişkenler bağlamında ele alınıp incelenecek ve çocuk gelişimi alanında önerilerde bulunulacaktır.

\section{Otobiyografik Bellek}

Bilgiyi (görülen, işitilen, düşünülen, hissedilen vb. şeyleri) alg1lama, düzenleme, kodlama, saklama ve hatırlama/tanımayla tanımlanan bilişsel süreç (Budak, 2003: 121) olan bellek ile ilgili alan yazın incelendiğinde, bellek ve bellek süreçlerini tanımlayan çok çeşitli kuramların olduğu görülmektedir. 
Atkinson-Shiffrin (1969)'in Bellek Modeli'ne göre, bellekte üç ana depolama alanı bulunmaktadır: Duyusal bellek, kısa süreli bellek ve uzun süreli bellek (Gluck, Mercado ve Myers, 2015: 352).

Uzun süreli bellek, ifade edilebilir (açık) ve ifade edilemeyen (örtük) bellek olmak üzere; ifade edilebilir bellek de, epizodik/anısal bellek ve semantik/anlamsal bellek olmak üzere iki kısma ayrılır. Örtük bellek, hazırlama, işlem belleği ve klasik koşullama olmak üzere üç kısma ayrılır (Dehn, 2010: 27). İfade edilebilir belleğe ait anılar kimliğimizi tanımlar; bilinçli olarak açıklanabilen anılar, belirli şeyler, insanlar ve belirli bir zaman ve yerdeki olayları (epizodik anılar) ve dünya hakkındaki genel bilgileri (semantik anılar) içerir. Ayrıca, açık/bildirilebilen anılar olarak da bilinir, çünkü bilinçli hatırlama gerektirirler. Bunlar Alzheimer hastalığında veya yaşlanma ile ilgili bellek kaybında kaybedilen anılardır. Bu tür anılar "kim, ne, ne zaman ve nerede" hakkında bilgi depolar ve beyinde hipokampusa bağlı öğrenme ve bellek sistemi tarafından işlenir (Alberini ve Travaglia, 2017: 5783).

Otobiyografik belleğe ait anılar, kişinin kendi geçmişindeki düşünceleri, duyguları ve davranışları hakkındaki anılarıdır (Budak, 2003: 554). Otobiyografik bellek, insanların kendi yaşamlarının önemli olaylarını ve deneyimlerini hatırlamalarını ifade eder; kişisel yaşam tarihlerini inşa etmelerine yardımcı olur ve deneyimlerini başkalarıyla ilişkilendirebilmelerini, sosyal olarak paylaşılan anılar yaratabilmelerini sağlar (Kail, 2012:216). Conway ve Pleydell-Pearce (2000)'in öne sürdüğü "Benlik Bellek Sistemi” (Self-Memory System) yaklaşımına göre, kişisel anılar soyuttan somut ve özele doğru (örneğin, yaşam öyküsü şeması, yaşam dönemleri, genel olaylar ve özel olay bilgisi) dört farklı hiyerarşik basamak boyunca depolanır. Yaşam öyküsü şeması, kişinin kendisini ifade eden, yaşam hikâyesini temsil eden bir öyküdür. Otobiyografik bellek temelinde oluşturulan benlik yapısı, kişinin benliğini, başkalarını, ilişkilerini ve dünyayı anlamaya yardım eden şemalardan oluşmaktadır.

Bireyin kendi yaşamındaki okul deneyimleri, okul arkadaşları, bisiklete binmeyi öğrenmesi veya büyükanne ve büyükbabaları ile olan anıları otobiyografik belleğe ait anılardır. Bu nedenle, otobiyografik belleğin hem epizodik hem de anlamsal bellekten gelen bilgileri kapsadığ1 düşünülmektedir. Otobiyografik bellek, benlik bilgisi ve bu kişisel bilgiyi çevreleyen anıların bilgisidir. Otobiyografik belleğe ait anılar, işlemsel öğrenme (araba kullanma, tenis oynama gibi) gibi diğer bilgi türlerini de temsil edebilir (Roediger ve Marsh, 2003: 476). Otobiyografik bellek, epizodik ve semantik belleğin üzerine kurulmuş ancak ötesine geçen bir kavramdır. Özel hatırlanan olaylar da dâhil olmak üzere, kişisel yaşamlarımız hakkında hatırladığımız bilgilerdir ve bundan daha fazlasıdır. Otobiyografik bellek, deneyimlerimizin bir sentezidir ve hoşlandıklarımızı, hoşlanmadıklarımızı ve tercihlerimizi içerir. Kimliğimize, benliğimize ve deneyimlerimize ilişkin bilgileri barındırarak bize rehberlik yapar, bizi bir anlamda bilgilendirir (Bailey ve Pransky, 2014: 
174). Yetişkinler, yedi yaşından itibaren deneyimledikleri olayları hatırlayabilir, mekânsal ve zamansal bağlamda yerleştirebilir ve bunlara bir dereceye kadar kişisel anlam ve önem yükleyebilir. Bununla birlikte, yedi yaşından önce, yetişkinlerin çoğu iki aşamalı amneziden mustariptir. İlk aşamadan itibaren (üç yaşından önce) yetişkinlerin kişisel veya otobiyografik anıları genellikle yoktur, varsa da çok azdır. İkinci aşamadan itibaren (üç-yedi yaş arası) yetişkinler, beklenenden daha az sayıda otobiyografik belleğe ait anılara sahiptir. Alan yazında, bu iki bölümden oluşan fenomen “İnfantil Amnezi” veya "Bebeklik/Çocukluk Amnezisi” olarak bilinmektedir (Bauer, 2008: 1).

\section{Bebeklik/Çocukluk Amnezisi}

Bilgiyi (görülen, işitilen, düşünülen, hissedilen vb. şeyleri) kodlamak, depolamak ve geri getirmek için gereken sinirsel "donanım", doğumda (ve öncesinde) mevcut olmasına rağmen, çok küçük çocukların belleği oldukça zayıftır. Bu erken dönem bellek zayıflığının "bebeklik/çocukluk amnezisi"ne yol açtığ1, yetişkinlerin bebeklik dönemlerinde ve yürümeye başlayan çocukların başlarına gelen olayları hatırlayamamaları, alan yazında üzerinde çok sayıda çalışmanın yapıldığı ve hem fikir olunduğu bir bulgudur (Schneider, 2015: 102)

Amnezi, kısmi veya tam bellek kaybı için kullanılan genel bir terimdir (Budak, 2003: 58). Teorik açıdan bakıldığında, bebeklik/çocukluk amnezisi ilginç ve önemlidir. Kendimizi uzayda ve zamanda sürekli olarak görmemize rağmen, bu sürekliliğin olmadığı bir gelişme noktası bulunmaktadır. Zamanın o anı, bebeklik/çocukluk amnezisinin sınırıdır. Bu nedenle Bebeklik/çocukluk amnezisi, gelişimdeki devamsızlığın açık kanıtı olarak değerlendirilir (Bauer, 2008: 1,2).

Bebeğin genetik özelliklerinin yanı sıra, fiziksel, bilişsel, sosyal, duygusal vb. gelişimsel süreçlerinin doğum öncesi dâhil olmak üzere çok sayıda faktörden etkilendiği bilinmektedir. Erken çocukluk döneminde bebekler/çocuklar her an, yeni bir uyaranla karşı karşıya kalmakta ve çeşitli öğrenme deneyimleri gerçekleştirmektedirler. Bu bağlamda, bilinçli olarak hatırlanamayan bebeklik/çocukluk dönemindeki birçok faktörün çocuğun gelişimini olumlu veya olumsuz etkilediği iyi bilinmektedir.

\section{Bebeklik/Çocukluk Amnezisini Ele Alan Teori ve Yaklaşımlar}

Freud, erişkin hastalarının ilk yaşam yıllarının anılarını nadiren hatırladığı (Altı-sekiz yaş öncesi) gözlemine dayanarak "İnfantil Amnezi Teorisi”ni geliştirmiştir. Bu teori, yüzyılı aşkındır farklı kültürlerde, farklı teknikler kullanılarak yapılan deneysel araştırmalar ile doğrulanmıştır (Josselyn ve Frankland, 2012: 423). Freud, erken yaşam döneminde oluşan deneyimlerin kişilerin yaşamları boyunca kalıcı bir etkisi olduğunu belirtmiştir ve yetişkin yaşamında erken deneyimlerinin oldukça 
etkili ve biçimlendirici olmasına rağmen bu dönemdeki deneyimlerin çok azını ya da hiçbir şeyini hatırlamamamızın paradoksal olduğunu belirtmiştir. Freud'a göre, ilk deneyimlerimiz bellekte saklanmaya devam ederek düşüncelerimizi ve davranışlarımızı etkilemeye devam etmekteydi, ancak ağırlıklı olarak cinsellik ve saldırganlık özellikleri nedeniyle bu anılar aktif olarak bilinçaltına itilmekteydi. Freud'un yetişkinlerin erken dönem yaşantılarına ait anılarının hatırlanamaması konusundaki açıklamaları artık yaygın olarak kabul edilmese de, fenomeni tanımlamak için kullandığı "Bebeklik/Çocukluk Amnezisi” terimi kalıcı mirasının bir parçasıdır (Jack ve Hayne, 2010:831).

Bebeklik/çocukluk amnezisi alanında yürütülen çalışmalarda, yaşam boyunca bebeklik/çocukluk deneyimlerinin beyin fonksiyonları için kritik öneme sahip olduğu belirtilmektedir. Bununla birlikte, hipokampusa bağlı öğrenme ve bellek sisteminin geliştirilmesinin altında yatan biyolojik mekanizmalar hakkında çok az şey bilinmektedir (Alberini ve Travaglia, 2017: 5783). Dikkat çekici olmasına rağmen, yetişkinlikte oluşan epizodik anılar yıllarca hatırlanabilirken, erken çocukluk döneminde oluşan benzer anılar kolay ve hızlı bir şekilde unutulmuş görünmektedir. Buna rağmen, erken yaşam dönemine ait deneyimlerin daha sonraki dönemlerde beyin fonksiyonlarını ve fizyolojisini derinden etkilediği belgelenmiştir. Örneğin, erken dönemde gerçekleşen tehdit edici deneyimler süreç içerisinde travma sonrası stres bozukluğu ve anksiyete bozuklukları gibi psikopatolojilere neden olabilir. Bu paradoks, erken dönem anılarının hatırlanamadıkları halde yetişkin yaşamını nasıl etkileyebileceği sorusunu gündeme getirmektedir. Bu paradoksu açıklamak için birkaç hipotez öne sürülmüştür. Bunlardan biri, bebeklik/çocukluk amnezisinin bebek beyninin olgunlaşmamış olmasından kaynaklandığını ileri sürmektedir (Travaglia, Bisaz, Sweet, Blitzer ve Alberini, 2016: 1225-1226). Son zamanlarda yapılan beyin araştırmaları, hipokampal nörogenezdeki (beyinde nöral kök hücrelerden fonksiyonel nöron oluşması) değişikliklerin de bu konuda önemli bir rol oynayabileceğini göstermektedir. Yapılan çalışmalar sonucunda belirtildiği gibi, hipokampal nörogenez oranları yaşamın erken döneminde yüksektir ancak, yaşla birlikte önemli ölçüde azalma gösterir. Bebeklik döneminde, nörogenez seviyeleri yükseldiğinde, hipokampusa bağlı ifade edilebilir belleğe ait anılar daha sonraki zamanlarda hatırlanamayabilir. Bu konuda hayvanlar üzerinde (fareler) yapılan deneysel çalışmalarda erken dönemde nörogenezisi azaltmanın hipokampusa bağı belleğin kalıcılığını artırdığını; yetişkin farelerde ise nörogenezisin artırılmasının unutmayı teşvik ettiğini belirtmektedir. Bu yeni ve ilginç bulgular, bebeklik/çocukluk amnezisi anlayışımıza katkıda bulunmakla birlikte, bebeklikten küçük çocukluğa geçişte gözlenen büyük bellek kaybını açıklamak için yeterli görünmemektedir (Schneider, 2015: 107). 
Bebeklik/çocukluk amnezisinin bir başka açıklaması, yetişkinlerin erken çocukluk ile ilgili pek çok anıya sahip olmadıklarını, çünkü genel bilişsel eksiklik nedeniyle yaşamın ilk yıllarında böyle bir anı repertuarı oluşmadığını göstermektedir. Örneğin, Piaget (1962), iki yaşından küçük çocukların bilişsel temsiller için bir kapasiteye sahip olmadığını önermiştir. Çok küçük çocukların, yokluğunda nesneleri ve olayları temsil edemedikleri varsayımına dayanarak, bu çocukların geçmiş olayları hatırlayamaması gerekir. Bu alanda yapılan çalışmaların bu klasik varsayımı desteklemediği belirtilmektedir (Schneider, 2015: 104). Yakın zamanda yapılan çalışmalarda, bebek beyninin olgunlaşmamış işlevleri arasında, hızlı unutmanın, uzun süreli belleğe ait anılanın depolanmasına ve bu anıların uzun süreli bellekteki kalıcılığına aracılık eden, bellek konsolidasyonunu (bilginin uzun süreli bellekte yerleşmesini ve sabit hale gelmesini sağlayan süreç) engellediği belirtilmektedir. Buna karşın, bazı araştırmacılar, bebeklik/çocukluk amnezisinin saklı, ifade edilmemiş bellek izlerinin yaşamda sonraki davranışları etkilemesini, bilginin uzun süreli bellekten geri getirilememesinden kaynaklandığını belirtmiştir. Bebeklik/çocukluk amnezisinin altında yatan mekanizmalar ve erken yaşamda edinilen bellek izlerinin depolanması hakkında çok az şey bilindiğinden bu paradoks çözülememiştir (Travaglia ve diğerleri, 2016: 1226).

Leichtman ve Ceci (1993)'ye göre bebeklik/çocukluk amnezisi, çocukların bilgi işleme sistemlerinin gelişiminin sonucudur. Bulanık İzler Teorisi (Fuzzy trace theory) bağlamında ele alındığında, yaşça daha küçük olan çocukların olayları fiziksel (verbatim) bellek izleriyle; yaşça daha büyük olan çocuk ve ergenlerin anlamsal (gist) bellek izleriyle kodladığı belirtilmektedir. Fiziksel kodlama, anlamsal kodlamaya göre daha çabuk kaybedildiği için bebeklik ve erken çocukluk döneminde depolanan bilgileri hatırlamak güçleşir. Bebeklik/çocukluk amnezisini açıklamada, bilişsel benlik algısının ortaya çıkması, dil becerilerinin kazanılması, nörobiyolojik olgunlaşma ve zihin kuramı gibi üst bilişsel beceriler de dâhil olmak üzere çeşitli faktörler öne sürülmüştür (Peterson, Warren, Nguyen ve Noel, 2010: 175). Bebeklik/çocukluk amnezisinin beynin erken gelişim döneminde fiziksel gelişimini tamamlayamamış olabileceği ve henüz anıları saklayamadığı için meydana geldiği belirtilmektedir. Gerçekten de hipokampusun tam olarak gelişebilmesi için birkaç y1l gerektiği belirtilmektedir (Richmond ve Nelson, 2007). Çok küçük çocukların genel gerçekleri (semantik bellek) hatırlayabildiklerini, ancak belirli olayları (epizodik bellek) hatırlayamadıkları ortaya konmuştur. Bu yüzden en eski anılar genel veya tipik olaylar için şemalara ve senaryolara dayanma eğilimindedir. İlgili alan yazın incelendiğinde, otizmli kişilerin otobiyografik bellek performanslarının otizmli olmayan kişilere göre daha düşük çıktığ1 görülmüştür (Crane ve Goddard, 2008; Goddard, Howlin, Dritschel ve Patel, 2000; Millward, Powell, Messer ve Jordan, 2000). Sosyal etkileşim ve iletişim problemlerinin görüldüğü nörogelişimsel bir bozukluk olan otizmli bireylerde 
gözlenen otobiyografik bellek yetersizlikleri otobiyografik bellek performansının dil ve beyin gelişimi ile ilişkisini ortaya koyması bakımından önemlidir.

Çok küçük çocukların anılarını saklayamamalarının bir başka olası nedeni de dil becerilerinin yetersizliği olabilir. Simcock ve Hayne (2003), 27-39 aylık çocuklara evlerinde "Sihirli Küçülen Makine (Magic Shrinking Machine)" ile ilgili bir dizi eylem göstermiş, 6-12 ay sonra çocuklarla görüşüp, onlardan bu deneyimlerini hatırlamalarını istemişlerdir. Çocukların hatırlama başarılarının ilk deneyim sırasındaki kelime dağarcıkları ile ilişkili olduğu görülmüştür. İlk değerlendirmede kelime dağarcı̆̆ı ve dil becerileri daha iyi olan çocukların kelime dağarcığı ve dil becerileri zayıf olan çocuklara göre daha fazla ayrıntıyı hatırlayabilip anlatabildikleri görülmüştür.

\section{Otobiyografik Belleğin Gelişimi}

Erken çocukluk döneminden itibaren gelişen, yetenekleri, tutumları ve değerleri içeren "benlik" kavramı ile otobiyografik bellek arasında doğrudan ilişki söz konusudur. Otobiyografik bellek gelişimi için, bebeklerin kendilerini aynada tanımaya başladıkları 18-24 ay arası önemlidir. Yapılan çalışmalarda kendilerini aynada tanıyan bebeklerin, kendilerini aynada tanımayan bebeklere göre ilerleyen dönemlerde daha iyi otobiyografik bellek performansları sergiledikleri görülmüştür. Deneyimin duygusal ve bilişsel durumlarına yapılan atıflar, benlik ve otobiyografik bellek anıları için önemlidir. Okul öncesi döneme doğru çocukların otobiyografik bellekleri incelendiğinde, duygusal ve bilişsel durumlarına daha sık başvuruda bulunarak, deneyime dair daha öz-yönelimli veya öznel bir bakış açısı geliştirdikleri görülmüştür. Bu durum, olayların otobiyografik bir kayda dâhil edilmesini kolaylaştırır, çünkü deneyimler yalnızca nesnel olaylar değil, özünde düşünce, duygu ve eylemlerin olduğu olaylardır. Ergenlik döneminde de öznel bakış açısında artış belirgindir (Bauer, 2014: 526).

Vygotsky ve Rogoff, gelişme ve öğrenmenin önce sosyal etkileşimler içinde gerçekleştiğini ve daha sonra benzer durumlarda çocuğun dâhil edildiğini ileri sürmüşlerdir. Otobiyografik Belleğin Sosyal Etkileşim Modeli'ne göre çocuklar, kişisel anılarının birbiriyle ilgisini geçmiş hakkında konuşarak öğrenilebilirler. Bu öğrenme süreci çocuklarla konuşmaya başladıktan kısa bir süre sonra, yetişkinçocuk sohbetlerinde geçmişle ilgili yapılan konuşmalarla gerçekleşebilir. Çocukların geçmişte yaşadıkları bir olayı anlatmaları, çocukluk döneminde görülür ve gelişmeye devam eder (Farrant ve Reese, 2000). Çocuklarda otobiyografik bellek becerilerinin gelişimindeki farklılıkları inceleyen çalışmalarda, annelerinin küçük çocuklarıyla birlikte yaşadıkları olaylar hakkında bilgi alma ve konuşma biçimlerindeki farklılıkların önemli olduğu belirtilmiştir. Çocuklarıyla konuşurken “düşük-ayrıntılı” konuşma tarzı benimseyen annelerin aksine, “yüksek-ayrıntıllı” konuşma tarzı 
benimseyen annelerin çocuklarına genellikle daha fazla soru sordukları, üzerinde konuşulan deneyimle diğer deneyimler arasında daha fazla ilişki kurdukları görülmüştür (Langley, Coffman ve Ornstein, 2017). Perner ve Ruffman (1995), otobiyografik belleğin ortaya çıkışını, çocukların gelişmeye başlayan üst-bilişsel süreçlerine özellikle de zihin teorisi (theory of mind) çerçevesinde meydana gelen gelişmelere bağlamıştır. Sosyo-dilbilimsel bakış açısına uygun olarak, çocukların başkalarıyla konuşmaları (özellikle anneler) zihin teorisi gelişimi için önemli bir veri kaynağı olarak hizmet etmekte, bunun sonucunda çocukların otobiyografik belleklerinin oluşmasına katkı sağlamaktadır.

Dil gelişimi, birbiriyle ilişkili üç nedenden dolayı otobiyografik belleğin gelişiminde kritik öneme sahiptir. İlk olarak dil, sadece anıların ifade edilme şekli olmayıp, kişisel deneyim için örgütsel bir yap1 sağlamada etkili bir bileşendir. İkinci olarak, dil, çocukların deneyimleri hakkında diğer insanlarla konuşmalarına izin verir ve bu konuşmalar, çocukların deneyimlerinin organize temsillerini oluşturmalarına yardımcı olur. Son olarak, bu konuşmalar çocuklar için anıların geçmişte meydana gelen olayları temsil etmesini ve birçok açıdan değerlendirilmesini sağlar (Fivush ve Nelson, 2004: 574).

Şekil 1'de görüldügü gibi, anıların bellekte kodlanması, saklanması ve geri getirilmesi için gerekli olan birçok bilişsel boyutun gelişiminin yeterli olabilmesinin beş yaşına kadar tamamlanabildiği belirtilmektedir. Çocuğun başkalarıly kurduğu iletişim ve etkileşim, dil gelişimi, bellek yap1 ve süreçlerinin gelişimi sonucu ortaya çıkan otobiyografik belleğin beş yıl boyunca gelişmeye devam etmesinin, otobiyografik belleğin gelişimsel sürecini açıklaması bakımından önemlidir. O zamana kadar çocuklar semantik ve belki de epizodik anılara sahip olabilirler, ancak anıları otobiyografik değildir. Özetle, bu bakış açılarının ortak noktası, yetişkinlerin erken çocukluk dönemini hatırlayamama nedeninin, çocuklar için mevcut olan bellek sisteminin oluşumu, saklanması ve daha sonra otobiyografik belleğe ait anıların alınması için gerekli bileşenlerden yoksun olduğu varsayımıdır. Sonuç olarak, sadece yetişkinler için değil aynı zamanda çocuklar için de yaşamın ilk yıllarından kalma otobiyografik belleğe ait anılar bulunmamaktadır (Nelson ve Fivush, 2004). 


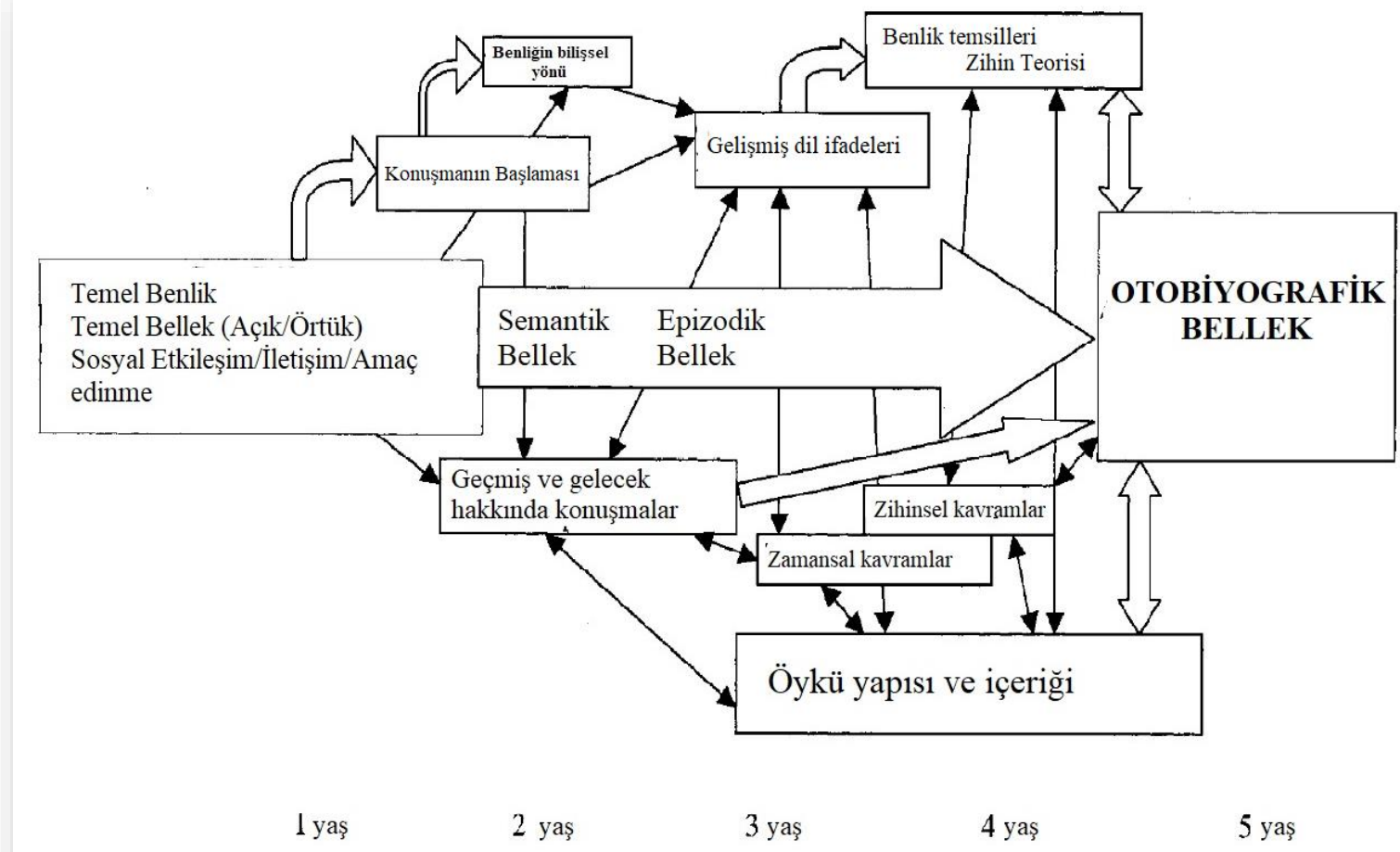

Şekil 1. Otobiyografik Belleğin İlk Beş Ylldaki Gelişimsel Süreci (Nelson ve Fivush, 2004: 490).

\section{Otobiyografik Bellek Gelişimini Etkileyen Faktörler}

Farklı kültürlerde yapılan çok sayıda çalışmada, otobiyografik bellek performanslarında kültürel farklılıklar olduğu belirlenmiştir. Bu konuda yapılan bazı çalışmalarda, batı kültürlerinde bireylerin anılarının daha erken döneme ilişkin olduğu daha uzun ve daha ayrıntılı içeriğe sahip olduğu belirlenmiştir (de la Mata ve diğerleri., 2018:1). Farklı kültürlere mensup katılımcıların yer aldığ1 çalışmalarda katılımcılara en erken çocukluk anılarının neler olduğu sorulduğunda, Koreli, Çinli ve Asyalıların, Avrupalı bireylerden yaklaşık altı aylık bir gecikme ile üç buçuk yaşından sonra meydana gelen olayları hatırladıkları görülmüştür. $\mathrm{Bu}$ gecikmenin Batılı bireylerin daha bireyselci yetiştirilmeleri nedeniyle meydana geldiği öne sürülmektedir (Wang, Conway ve Hou, 2004: 123). Batı kültürlerinde yetişen bireylerin kendi eylemlerine, düşüncelerine ve duygularına odaklanan ayrıntılı ve özel otobiyografik belleğe ait anıları anlattıkları; doğu kültürlerinde yetişen bireylerin ise kendi eylemlerini göz önünde bulundurarak daha genel, daha az ayrıntılı ve grup normları ve ihtiyaçları ile ilgili olarak daha ortak bir çerçeveye yerleştirilmiş otobiyografik belleğe ait anıları anlattıkları belirtilmiştir (Wang ve Ross 2007). 
Bazı araştırmacılar, kadınların erkeklere göre bebeklik anılarını daha çok hatırlayabildiklerini belirtmekte, bazı araştırmacılar ise kadınlar ve erkekler arasında bu konuda herhangi bir fark olmadığını belirtmektedir. Bebeklik anılarının daha fazla hatırlanmasının nedeni, hem anne hem de babaların kızlarıyla olan anıları oğullarıyla olan anılarından daha sık paylaşmalarına ve konuşmalarına bağlanmıştır. Bunlara ilaveten kadınların olumsuz olma ihtimali olan olaylar hakkında anılarının daha fazla olduğu da belirtilmektedir (Peterson, Grant ve Boland, 2005:624).

\section{SONUÇ ve TARTIŞMA}

İnsanların geçmişine ait anıları, geçmişlerini anlamalarına yardımcı olmakla kalmaz, aynı zamanda yaşamlarındaki kimlik, süreklilik ve tutarlılık bileşenlerine de önemli katkılarda bulunur. Kişiliğin ayrılmaz bir parçası olan otobiyografik bellek performansları daha iyi olan kişilerin sosyal becerilerinin de daha iyi olduğu bilinmektedir. Erken dönem yaşantıları ve anıları bilişsel, sosyal ve duygusal gelişimin birçok yönü için biçimlendiricidir ve uzun süren etkilere neden olabilir (Peterson ve Nguyen, 2010:719).

İnsanların yaşam süresinin küçük bir bölümü olan bebeklik ve çocukluk dönemi, daha büyük bir süreye karşılık gelen yetişkinlik ve yaşll1ık dönemindeki davranış ve alışkanlıkların temelini oluşturması bakımından önemlidir. Bireylerin bebeklik ve çocukluk döneminde karşılaştığı birçok uyaran ve deneyimlediği yaşantılar bilinçli olarak hatırlanamamaktadır, ancak hamilelik döneminden itibaren bebek/çocukların temel bakım, sağlık, eğitim, ilgi ve sevgi gibi ihtiyaçlarının zamanında, yeterli ve tutarlı biçimde karşılanması önemlidir.

İlgili alan yazın incelendiğinde, bebeklik/çocukluk amnezisini açıklamada bazı bütünleşik teorilerin nöral, bilişsel, dilbilimsel ve sosyal faktörler arasında karmaşı bir etkileşime girerek birlikte çocukluk çağında daha dayanıklı anıların kademeli olarak ortaya çıkmasına neden olduğunu ileri sürdükleri görülmektedir. Bu teorilerde, çocukların otobiyografik anılarını güçlendirmek ve unutmaya karşı korumak için farklı yaşlarda birçok etkinin aktif hale geldiği belirtilmektedir. $\mathrm{Bu}$ teorilerde ayrıca, sosyal hatırlama çevresi ön plana çıkmakta ve özellikle ebeveynlerin olayları çocuklarıyla olduğu gibi veya kısa bir süre sonra meydana geldiği olaylarla üzerinde konuştukları ayrıntı düzeyi önemlidir (Reese ve Robertson, 2019: 80).

Son zamanlarda otobiyografik bellek gelişimi ile ilgili yapılan çalışmalarda, özellikle ebeveynler ve çocuklar arasında ayrıntılı ve kapsamlı olan konuşmaların, çocukların bellek becerilerini desteklediği belirtilmektedir. Ayrıca, daha iyi bellek becerilerinin daha erken dönem anılarının hatırlanmasına neden olabileceği belirtilmektedir (Peterson ve diğerleri., 2010: 175). 
Çocukluk döneminden itibaren otobiyografik bellek, karşılaşılan olayları anlama, anlamlandırma ve problemleri çözmede bireysel farkl1lıklar ortaya çıkarmak suretiyle kolaylık sağlar. Düşünce, duygu ve davranışları düzenleme becerisi olan öz-düzenleme de otobiyografik bellek sayesinde gerçekleşmektedir. Sosyal ilişkiler için önemli olan otobiyografik bellek gelişimi için ebeveynler erken dönemden itibaren çocuklarıyla yaşanılan olaylar hakkında sohbet edebilirler. Çocuklarla sohbet edilirken düşük ayrıntılı konuşma yerine yüksek ayrıntılı konuşmanın yapılması önemlidir. Çocuklarla kurulan iletişimde çocuğun edindiği deneyim ve yaşantılarla ilgili olarak çocuklara daha fazla sayıda ve açık uçlu soru sormak, edindiği deneyimi önceki yaşantılarıyla ve gelecekte yaşanma olasılığı olan olaylarla ilişkilendirme yapmalarını sağlamak, ebeveynin ya da çocukla iletişime geçen yetişkinin kendi otobiyografik bellek süreçlerinden yararlanarak örnek vermesi de oldukça önemlidir. Çocuklarla birlikte çekilen fotoğraf ve videoları incelemek, üzerinde konuşmak da otobiyografik belleği güçlendirebilir. Otobiyografik bellek sayesinde paylaşılan kişisel anılar sosyal bağları güçlendirir, dil gelissimini olumlu anlamda etkiler ve çocuğun çevresine ve kendisine olan güvenini artırır. Çocuklar, erken dönemden itibaren geçmişini iyi değerlendirebilir, doğru ve hatalı davranışlarından dersler çıkarıp, yerinde kararlar alıp uygulayabilir.

Son olarak; bebeklik/çocukluk amnezisinin bitimi, otobiyografik belleğin başlangıcı olan döneme denk gelen erken çocukluk döneminde, çocukların bilişsel, duygusal, sosyal ve dil gelişimleri ile otobiyografik bellek performansları arasındaki ilişkiler ile ihmal, istismar, göç, travmatik yaşantılara maruz kalma, evlat edinilme, anne babanın ölümü gibi çeşitli nedenlerle anne babadan ayrı kalma gibi çocukların yaşantılarını derinden etkileyebilen farklı değişkenler ile otobiyografik bellek ilişkilerini ele alan çalışmaların yapılmasının özellikle ulusal alan yazınına katkı sağlayacağı düşünülmektedir. 


\section{KAYNAKÇA}

Alberini, C., \& Travaglia, A. (2017). Infantile amnesia: A critical period of learning to learn and remember. Journal of Neuroscience,37(24), 5783-5795.

Bailey, F. \& Pransky, K. (2014). Memory at work in the classroom: Strategies to belp underachieving students. Alexandria, VA: Association for Supervision and Curriculum Development.

Bauer, P. J. (2014). The development of forgetting: childhood amnesia. İçinde P. J. Bauer \& R. Fivush (Eds.), The wiley handbook on the development of children's memory (s. 519-544). UK: WileyBlackwell.

Bauer, P. J. (2015). A complementary processes account of the development of childhood amnesia and a personal past. Psychological Review,122, 204-231.

Bauer, P. J. (2008). Infantile amnesia. İçinde M. M. Haith \& J. B. Benson (Eds.), Encyclopedia of infant and early childhood development (s. 51- 62). San Diego, CA: Academic Press. http://dx.doi.org/10.1016/B978-012370877-9.00007-4

Budak, S. (2003). Psikoloji sözliüğ̈. Ankara: Bilim ve Sanat.

Conway, M. A., \& Pleydell-Pearce, C. W. (2000). The construction of autobiographical memories in the selfmemory system. Psychological Review, 107, 261-288.

Crane, L., \& Goddard, L. (2008). Episodic and semantic autobiographical memory in adults with autism spectrum disorders. Journal of Autism and Developmental Disorders, 38(3), 498-506. doi:10.1007/s10803-007-0420-2.

Dehn, M.J. (2010). Long-term memory problems in children and adolescents assessment, intervention, and effective instruction. Hoboken, New Jersey: Wiley.

de la Mata, M. L., Santamaría, A., Trigo, E. M., Cubero, M., Aria, S., Antalíková, R., ... Ruiz, M. L. (2019). The relationship between sociocultural factors and autobiographical memories from childhood: The role of formal schooling. Memory, 27 (1), 103-114.

Farrant, K., \& Reese, E. (2000). Maternal Style and Children's Participation in Reminiscing: Stepping Stones in Children's Autobiographical Memory Development. Journal of Cognition and Development, 1(2), 193-225. 
Fivush, R., \& Nelson, K. (2004). Culture and language in the emergence of autobiographical memory. Psychological Science, 15, 573-577.

Gluck, M.A., Mercado, C. ve Myers, C.E. (2015). Learning and memory: From brain to behavior (3rd Ed.). New York: Worth Publishers.

Goddard, L., Howlin, P., Dritschel, B., \& Patel, T. (2007). Autobiographical memory and social problem solving in asperger syndrome. Journal of Autism and Developmental Disorders, 37(2), 291-300.

Jack, F., \& Hayne, H. (2010). Childhood amnesia: Empirical evidence for a two-stage phenomenon. Memory, 18 (8), 831-844, doi: 10.1080/09658211.2010.510476

Josselyn, S.A.\& Frankland, P.W. (2012). Infantile amnesia: A neurogenic hypothesis. Learning \& Memory, 19, 423-433.

Kail, R. V. (2012). Children and their development. Boston, MA: Pearson.

Langley, H. A., Coffman, J. L., \& Ornstein, P. A. (2017). The socialization of children's memory: Linking maternal conversational style to the development of children's autobiographical and deliberate memory skills. Journal of Cognition and Development, 18(1), 63-86. doi: $10.1080 / 15248372.2015 .1135800$

Leichtman, M. D., \& Ceci, S. J. (1993). The problem of infantile amnesia: Lessons from fuzzytrace theory. In M. L. Howe \& R. Pasnak (Eds.), Emerging themes in cognitive development (Vol. 1, pp. 195213)., Foundations New York: Springer.

Millward, C., Powell, S., Messer, D., \& Jordan, R. (2000). Recall for self and other in autism: Childrens memory for events experienced by themselves and their peers. Journal of Autism and Developmental Disorders, 30, 15-28.

Nelson, K., \& Fivush, R. (2004). The emergence of autobiographical memory: A social cultural developmental theory. Psychological Review, 111, 486 -511. http://dx.doi.org/10.1037/0033295X.111.2.486.

Perner, J., \& Ruffman, T. (1995). Episodic memory and autonoetic consciousness: Developmental evidence and a theory of childhood amnesia. Journal of Experimental Child Psychology, 59, 516-548. 
Peterson, C., \& Nguyen, D.T. (2010). Parent-child relationship quality and infantile amnesia in adults British Journal of Psychology, 101, 719-737.

Peterson, C., Warren, K., Nguyen, D. T., \& Noel, M. (2010). Infantile amnesia and gender: Does the way we measure it matter? Procedia-Social and Behavioral Sciences, 9, 1767-1771.

Peterson, C., Grant, V., \& Boland, L. (2005). Childhood amnesia in children and adolescents: Their earliest memories. Memory, 13 (6), 622-637. Doi: 10.1080/09658210444000278

Reese, E., \& Robertson, S.-J. (2019). Origins of adolescents' earliest memories. Memory, 27 (1), 79 91. doi:10.1080/09658211.2018.1512631

Richmond, J., \& Nelson, C. A. (2007). Accounting for change in declarative memory: A cognitive neuroscience perspective. Developmental Review, 27, 349-373.

Roediger, H. L., \& Marsh, E. J. (2003). Episodic and autobiographical memory. İçinde I. B. Weiner (Ed.), Handbook of Psychology: Vol. 4. Experimental psychology (3rd ed., s. 475-497). New York, NY: Wiley.

Schneider, W. (2015). Memory development from early childhood through emerging adulthood. Cham, Switzerland: Springer International Publishing.http://dx.doi.org/10.1007/978-3-319-09611-7

Simcock, G. and Hayne, H. (2003). Age-related changes in verbal and non-verbal memory during early childhood. Developmental Psychology, 39, 805-814.

Travaglia, A., Bisaz, R., Sweet, E.S., Blitzer, R.D., Alberini, C.M. (2016). Infantile amnesia reflects a developmental critical period for hippocampal learning. Nature Neuroscience, 19, 1225-1233.

Wang, Q., Conway, M. A., \& Hou, Y. (2004). Infantile amnesia: A cross-cultural investigation. Cognitive Sciences, 1, 123-135.

Wang, Q., \& Ross, M. (2007). Culture and memory. İçinde S. Kitayama, D. Cohen (Ed.) Handbook of Cultural Psychology (s. 645-667). New York: Guilford. 